\title{
THE IMPORTANCE OF SEGREGATION, DISCRIMINATION, PEER DYNAMICS, AND IDENTITY IN EXPLAINING TRENDS IN THE RACIAL ACHIEVEMENT \\ GAP
}

\author{
Roland G. Fryer, Jr \\ Working Paper 16257 \\ http://www.nber.org/papers/w16257
}

\author{
NATIONAL BUREAU OF ECONOMIC RESEARCH \\ 1050 Massachusetts Avenue \\ Cambridge, MA 02138
}

August 2010

I am grateful to all my colleagues and coauthors whose ideas, intuition, and work fill this chapter. Meghan Howard provided truly exceptional research assistance. Financial support through the Education Innovation Laboratory (EdLabs) is gratefully acknowledged. Correspondence can be addressed to the author at: Department of Economics, Harvard University, 1805 Cambridge Street, Cambridge MA, 02138. The usual caveat applies. The views expressed herein are those of the author and do not necessarily reflect the views of the National Bureau of Economic Research.

NBER working papers are circulated for discussion and comment purposes. They have not been peerreviewed or been subject to the review by the NBER Board of Directors that accompanies official NBER publications.

(C) 2010 by Roland G. Fryer, Jr. All rights reserved. Short sections of text, not to exceed two paragraphs, may be quoted without explicit permission provided that full credit, including $\odot$ notice, is given to the source. 
The Importance of Segregation, Discrimination, Peer Dynamics, and Identity in Explaining Trends in the Racial Achievement Gap

Roland G. Fryer, Jr

NBER Working Paper No. 16257

August 2010

JEL No. J01,J15

\section{ABSTRACT}

After decades of narrowing, the achievement gap between black and white school children widened in the 1990s - a period when the labor market rewards for education were increasing. This presents an important puzzle for economists. In this chapter, I investigate the extent to which economic models of segregation, information-based discrimination, peer dynamics, and identity can explain this puzzle. Under a reasonable set of assumptions, models of peer dynamics and identity are consistent with the time-series data. Segregation and models of discrimination both contradict the trends in important ways.

Roland G. Fryer, Jr

Department of Economics

Harvard University

Littauer Center 208

Cambridge, MA 02138

and NBER

rfryer@fas.harvard.edu 


\section{Trends in the Racial Achievement Gap}

The racial achievement gap in education is a sobering reality. At nine months old, there are no detectable cognitive differences between black and white babies (Fryer and Levitt, forthcoming). Differences emerge as early as age two, and by the time black children enter kindergarten they are lagging whites by 0.64 standard deviations in math and 0.40 in reading (Fryer and Levitt, 2004). On every subject at every grade level, there are large and important achievement differences between blacks and whites that continue to grow as children progress through school (Campbell, Hombo, and Mazzeo, 2000; Neal, 2006). Even accounting for a host of background factors, the achievement gap remains large and statistically significant (Jencks and Phillips, 1998).

Figure 1: Black-White Achievement Gaps in NAEP

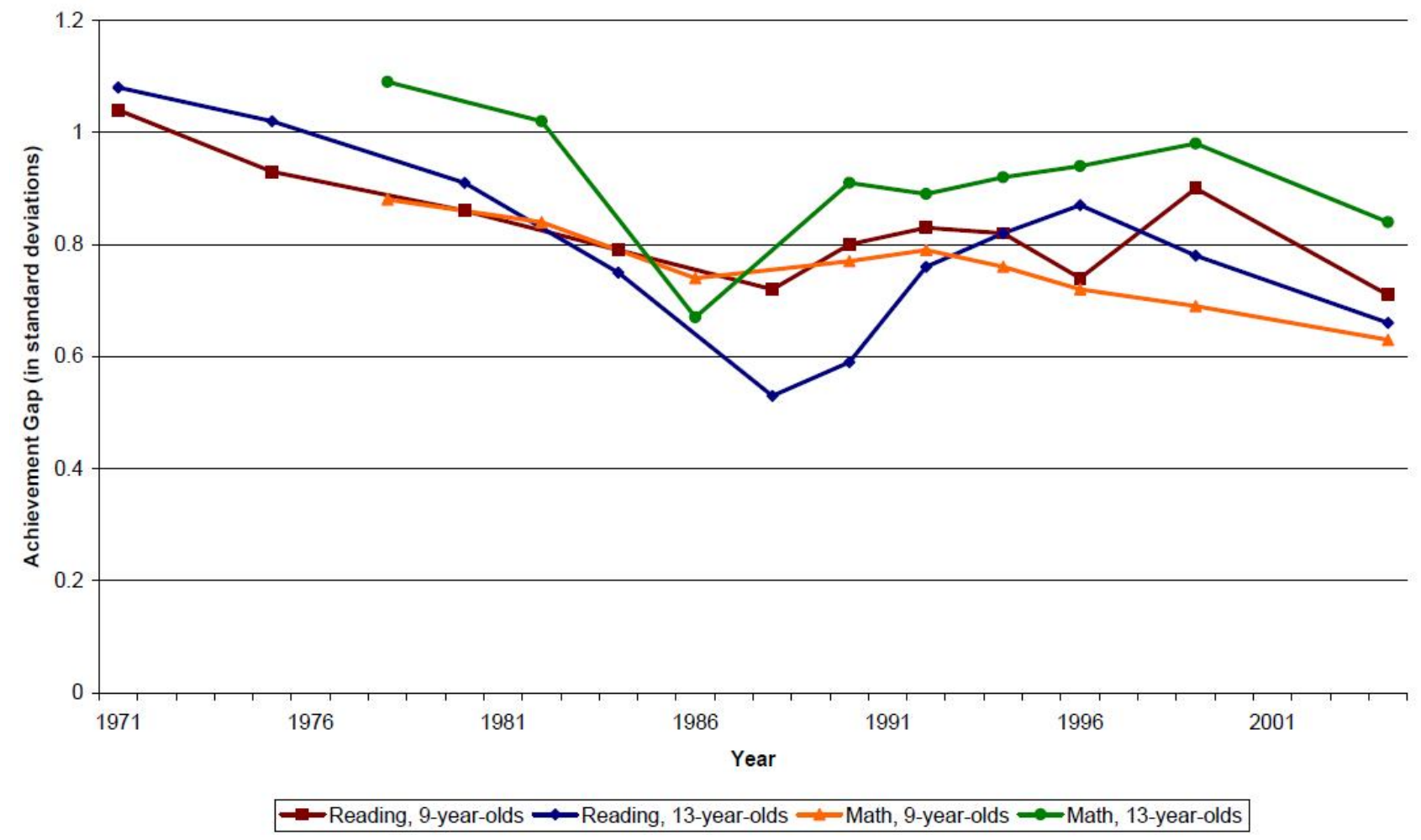

The above facts about the achievement gap are relatively well-known. More surprising is the evidence presented in Neal (1999) that illustrates that after decades of narrowing, achievement gaps between blacks and whites widened in the 1990s, precisely during a time when the premium on education had increased. Figure 1, using data from nine and thirteen 
year olds born between 1958 and 1995 in the National Association of Education Progress (NAEP), shows that cohorts born between the 1970s and 1980s experienced a consistent decrease in the black-white gap when they took the NAEP at age nine, and a generally decreasing trend in the gap for the NAEP administered at age thirteen. For those born after 1980, however, the trend reverses and the black-white achievement gap widens during a period when the premium on skills had increased. In the most recent years of the timeseries, achievement gaps seem to be converging again.

Understanding the slow down in the convergence of racial achievement gaps is an important open question ${ }^{1}$ The answer may provide significant clues for our understanding of racial inequality writ large (Neal and Johnson, 1996; Neal, 1999; Fryer, forthcoming).

In this chapter, we investigate the extent to which economic models of segregation, information-based discrimination, peer dynamics, and identity can explain the striking trends in the achievement gap. For pedagogical purposes, we provide important details of these classes of models and a more speculative discussion that suggests models of peer dynamics or identity have the potential to explain trends in the racial achievement gap.

\section{Segregation}

Ethnic and racial segregation is an important and well-studied social phenomenon. For over 50 years, social scientists have been concerned with measuring the extent of, and estimating the impact of, segregation in education, housing, and the labor market. The result of this scholarship has been nearly 20 different indices of segregation, and a general consensus that the spatial separation of many minorities from jobs, role models, health care, and quality local public goods is a leading cause of racial and ethnic differences on many economic, social, and health related outcomes (Almond, Chay, and Greenstone, 2003; Borjas, 1995; Case and Katz, 1991; Kain, 1968; Cutler and Glaeser, 1997; Massey and Denton, 1993; Collins and Williams, 1999). To the extent that segregation plays a significant role in for skill development, it may partially explain the puzzle put forth in the introduction.

From 30,000 feet, segregation is the degree to which two or more groups are separated from each other. Massey and Denton (1988) group existing indices into five classes: evenness, exposure, concentration, centralization, and clustering, which they take to resemble the totality of what is usually meant by "segregation." Evenness refers to the differential distribution of two groups across areas in a city. Measures of exposure are designed to approximate the amount of potential contact and interaction between members of different groups. Concentration indices measure the relative amount of physical space occupied by

\footnotetext{
${ }^{1}$ Neal (1999) investigates a similar question using different economic models.
} 
a minority group. Centralization is the extent to which a group is located near the center of an urban area, and clustering measures the degree to which geographic units inhabited by minority members abut one another, or cluster spatially. Below, we provide a formal definition of an index in each of these five classes.

The most popular measure of segregation is the "dissimilarity" index (developed by Jahn, Schmid, and Schrag (1947)), a measure of evenness.2 Suppose a city is divided into $N$ sections. The dissimilarity index measures the percentage of a group's population that would have to change sections for each section to have the same percentage of that group as the whole city. In symbols:

$$
\text { index of dissimilarity }=\frac{1}{2} \sum_{i=1}^{N}\left|\frac{\text { black }_{i}}{\text { black }_{\text {total }}}-\frac{\text { nonblack }_{i}}{\text { nonblack }_{\text {total }}}\right|
$$

where $b l a c k_{i}$ is the number of blacks in area $i, b_{\text {ack }} k_{\text {total }}$ is the total number of blacks in the

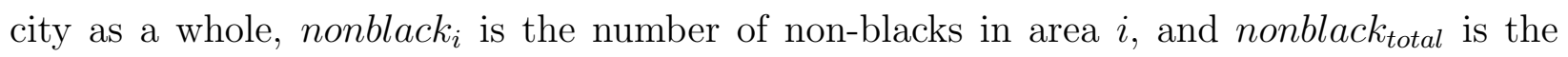
number of non-blacks in the city. The dissimilarity index has the appealing feature that it is invariant to the size of a minority group.

A second commonly-used measure of segregation is "isolation," a measure of exposure. As Blau (1977) recognized, blacks can be evenly distributed among residential areas in a city, but experience little exposure to non-blacks if they are a relatively large proportion of the city. Isolation measures the extent to which blacks are exposed only to one other, rather than to non-blacks. The index is computed as the minority-weighted average of each section's minority population:

$$
\text { index of isolation }=\sum_{i}\left(\frac{\text { black }_{i}}{\text { black }_{\text {total }}} \cdot \frac{\text { black }_{i}}{\text { person }_{i}}\right),
$$

where person $_{i}$ refers to the total population of area $i .^{3}$

A third measure of segregation is the "Delta" index - a measure of concentration - originally proposed by Hoover (1941). The index is similar to the dissimilarity index. Suppose that two cities have the same minority proportion and an equivalent degree of evenness, but in one city minority areas are few in number and small in area, while in the other city they

\footnotetext{
${ }^{2}$ Other measures of evenness include the Gini coefficient (the mean absolute difference between minority proportions weighted across all pairs of geographic units, expressed as a proportion of the maximum weighted mean difference), the Atkinson index (similar to Gini coefficient, but allows researchers to decide how to weight geographic units which are over or under the city-wide distribution) (Atkinson, 1970), and Entropy (the weighted average of each geographic units deviation from the racial entropy of the city as a whole).

${ }^{3}$ Another commonly used measure of exposure is the interaction index, which is the inverse of the isolation index presented above.
} 
are large and numerous. The former city is likely to be considered more segregated than the latter. The following index formalizes this intuition:

$$
\text { delta index }=\frac{1}{2} \sum_{i}\left|\frac{\text { black }_{i}}{\text { black }_{\text {total }}}-\frac{\text { area }_{i}}{\text { area }_{\text {total }}}\right|
$$

A fourth measure of segregation is the index of absolute clustering in urban spaces - the extent to which census regions inhabited by minorities abut one another. In symbols:

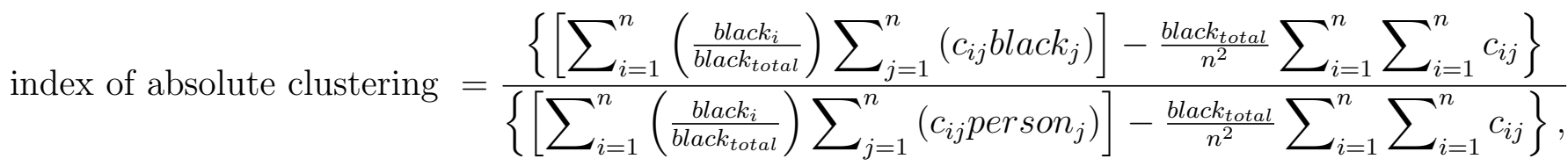

where $c_{i j}$ refers to an element in a "contiguity matrix" that equals one when census units $i$ and $j$ are contiguous and zero if not. The final measure is an index of centralization - developed by Massey and Denton (1988). The simplest and most widely reported centralization measure is:

$$
\text { index of absolute centralization }=\left(\sum_{i=1}^{n} \operatorname{black}_{i-1} A_{i}\right)-\left(\sum_{i=1}^{n} \operatorname{black}_{i} A_{i-1}\right)
$$

where the $N$ areas are ordered 1 to $N$ by increasing distance from the center city and $A_{i}$ refers to the cumulative proportion of land area through unit $i$. This index, which can be applied to any racial group, provides an absolute measure of how residents of a particular demographic live in relation to the center city.

Figure 2: A Hypothetical City

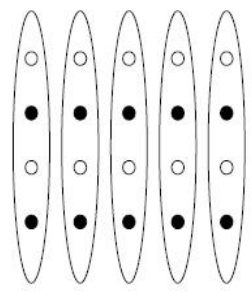

A

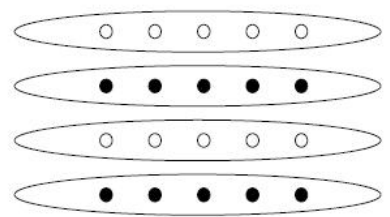

B

Of the five dimensions of segregation, only two are used in the vast majority of applied work in the social sciences: evenness and exposure. Yet, these indices have at least two undesirable properties. First, they explicitly depend on the arbitrary ways in which cities 
can be partitioned into sections (e.g. census tracts). 4 That is, fixing the location of minorities and non-minorities in a city and re-drawing the sections can drastically change the measure of segregation. An exaggerated example is depicted in figure 2. The city depicted in the figure has a dissimilarity index of 0 - perfect integration - when sections are drawn vertically and has a dissimilarity index of 1 - extreme segregation - when sections are drawn horizontally; no household has moved. Similarly, vertical partitions yield an isolation index of .5 whereas horizontal partitions produce an index of 1 . This is a highly undesirable property of any segregation index, as it may artificially indicate that a city is more or less segregated as a function of how the tracts are drawn. An important drawback is that there is no theory of how the city should be partitioned.

Second, existing measures are not defined when trying to measure segregation at the level of individuals. It is difficult to correctly identify the relationship between segregation and outcomes without individual-level variation in segregation. As a descriptive matter, individual segregation may be more useful than city-wide segregation. Rather than correlate individual economic outcomes with city-wide segregation, one can correlate individual outcomes with individual measures of segregation. [ $^{5}$

A recent paper develops a measure of segregation based on social interactions that builds on some of the weaknesses of dissimilarity and isolation, while incorporating elements of traditional measures of concentration and clustering (Echenique and Fryer, 2007). To fully understand the measure, we need a bit of a model.

\section{Basic Building Blocks}

The basic building blocks are a finite set of individuals, $V$, and information on whether (and, possibly, how much) any two individuals interact. The measure, coined the spectral segregation index, depends on the network of social interactions among the individuals in $V$. Like measures of exposure, the Spectral index identifies segregation of the members of a group with the intensity of the social interactions among the members of that group.

Given any two individuals, suppose we know whether they interact with each other and the intensity of their interaction. For any two individuals $v$ and $v^{\prime}$ in $V$, let the number $r_{v v^{\prime}} \geq 0$ represent the fraction of their social interactions $v$ and $v^{\prime}$ spend together. If $r_{v v^{\prime}}=0$, then there are no interactions between $v$ and $v^{\prime}$; if $r_{v v^{\prime}}>0$ then $v$ and $v^{\prime}$ have a relationship. Abusing notation, let $V$ to refer to the number of elements in the set $V$. The information

\footnotetext{
${ }^{4}$ We are not the first to draw attention to this flaw in measures of segregation, see Cowgill and Cowgill (1951), Appendix A in Taeuber and Taeuber (1965), and Massey and Denton (1988). While this property is problematic for measures of residential segregation, it is less likely to effect measures of occupational or school segregation - where there is a natural clustering of individuals.

${ }^{5}$ This critique is conceptual - not purely data driven. Existing measures are not equipped to measure segregation at the level of individuals, irrespective of the available data.
} 
on interactions is then summarized in a $V \times V$ matrix $R$, with typical element $r_{v v^{\prime}}$, where $\sum_{v^{\prime} \in V} r_{v v^{\prime}}=1$.

Now, suppose that we know the race of each individual $v \in V$. Fix a race, called race $h$, and drop from the set $V$ all individuals from races other than $h$. Form the matrix $B$ from the matrix $R$ by retaining only those $r_{v v^{\prime}}$ for which both $v$ and $v^{\prime}$ belong to race $h$. The matrix $B$ (a submatrix of $R$ ) reflects the network of same-race social interactions among the members of race $h$.

A segregation index for race $h$ is a function that assigns a real number $S^{h}(B)$ to each matrix $B$ of same-race interactions, along with functions assigning a real number $s_{v}^{h}(B)$ for each individual member $v$ of race $h$, such that $S^{h}(B)$ is the average of the individual $s_{v}^{h}(B)$. Individual segregation is measured in the same units as racial segregation; race- $h$ segregation is simply the average of the individual $s_{v}^{h}(B)$.

\section{Three Properties Which Define The Spectral Segregation Index}

The first property requires that an increase in the intensity of same-race interactions imply an increase in segregation. Concretely, say that a matrix $B^{\prime}$ has more intense interactions than matrix $B$ if all the entries of the matrix $B^{\prime}$ are at least as large as those of $B$. Then, if $B=\left(r_{v v^{\prime}}\right)$ and $B^{\prime}=\left(r_{v v^{\prime}}^{\prime}\right)$ we have $r_{v v^{\prime}} \leq r_{v v^{\prime}}^{\prime}$ for all $v$ and $v^{\prime}$. A segregation index satisfies the property of monotonicity if, whenever $B^{\prime}$ has more intense interactions than $B$, $S^{h}(B) \leq S^{h}\left(B^{\prime}\right)$.

The second property is a normalization of the index. Let $d>0$ be a real number. A matrix $B$ is homogeneous of degree $d$ if, for all $v$ in race $h, \sum_{v^{\prime}} r_{v v^{\prime}}=d$. An example of a homogeneous of degree $3 / 4$ matrix is

$$
\left(\begin{array}{ccc}
0 & 1 / 4 & 1 / 2 \\
1 / 4 & 0 & 1 / 2 \\
1 / 2 & 1 / 4 & 0
\end{array}\right)
$$

A segregation index is homogeneous if, whenever $B$ is homogeneous of degree $d, S^{h}(B)=d$.

Homogeneous networks rarely occur in practice, but the property gives an interpretation to the segregation of networks one encounters in applications. For example, a measure of 0.8 can be read as the segregation race- $h$ individuals would have if they spent 80 percent of their time with individuals of the same race. Homogeneity also provides a "scale free" property: If City $A$ has more households than City $B$, but each household in both cities has the same fraction of same-race neighbors, the index will report the same level of segregation for both cities.

Let $N_{v}$ be the set of individuals of race $h$ that $v$ interacts with: the set of $v^{\prime}$ in race 
$h$ with $r_{v v^{\prime}}>0$. In a similar vein, consider the set of individuals who interacts with the members of $N_{v}$, and those that interact with those that interact with the members of $N_{v}$, and so on. The resulting set of individuals, with direct or indirect interactions with $v$, is called the connected component of $B$ that $v$ belongs to; denote this set of individuals by $C_{v}$.

The third property requires that $s_{v}^{h}(B)$ be the average of $s_{v^{\prime}}^{h}(B)$ among $v$ 's race- $h$ social interactions, relative to the average segregation of the individuals in $v$ 's connected component. If $S^{C_{v}}$ is the average segregation of individuals in $C_{v}$, say that a segregation index satisfies linearity if

$$
s_{v}^{h}(B)=\frac{1}{S^{C}} \sum_{v^{\prime} \in N_{v}} r_{v v^{\prime}} s_{v^{\prime}}^{h}(B) .
$$

The spectral segregation index (SSI) is the (unique) segregation index that satisfies the properties of monotonicity, homogeneity, and linearity (Theorem 1, Echenique and Fryer, 2007).

On a connected component, SSI is the largest eigenvalue of the corresponding irreducible submatrix of $B$. The individual SSI are obtained by distributing the component's SSI among individuals using the eigenvector corresponding to the largest eigenvalue. Thus, SSI results from familiar matrix operations and is easy to compute using standard software.

\subsection{The Impact of Segregation on Achievement}

There is an impressive literature on the effects of segregation across schools on achievement. Jonathan Guryan (2004) estimates that half of the decline in black dropout rates between 1970 and 1980 is attributable to desegregation plans. Robert Crain and Jack Strauss (1985) find that students randomly offered the chance to be bussed to a suburban school were more likely to work in professional jobs nearly 20 years after the experiment. Christopher Jencks (1972) estimates that desegregation raises black achievement by 2-3 percent. Card and Rothstein (2007) show that roughly one-quarter of the racial gap in Scholastic Aptitude Test (SAT) scores can be eliminated by shifting students from a highly segregated city to an integrated city. Based on a meta-analysis of ninety-three studies, Robert Crain and Rita Mahard (1981) conclude that desegregation has a significant effect on black achievement, especially younger children, though other meta-analyses are less conclusive (St. John, 1975).

Whether or not segregation can explain the stagnation in the convergence of black and white test scores is an open question for which we do not have solid evidence. There are at least three potential scenarios: (1) the quantity of residential segregation increased during the late 1980s and early 1990s which corresponds with the widening of the achievement gap; (2) residential segregation has remained constant but segregation in social contacts within 
schools have increased; or (3) the price of segregation increased during the relevant years.

Figure 3: Indices of Racial Segregation, 1980-2000

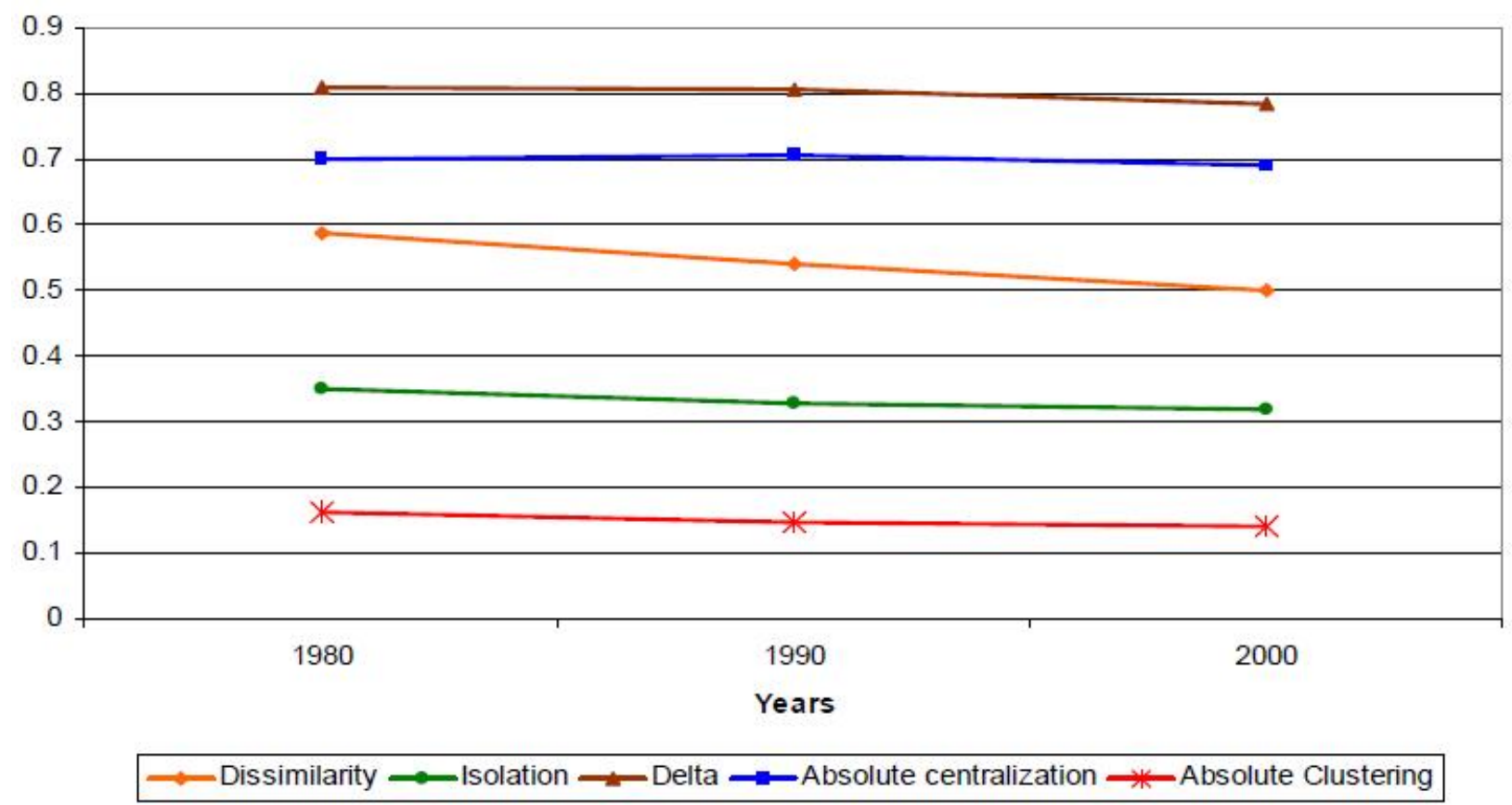

Figure 3 provides trends in segregation for the five measures described above: dissimilarity, isolation, delta, absolute centralization, and absolute clustering. All these measures follow a similar downward trend; America is becoming less racially segregated. Thus, the data from figure 3 lead one to conclude that the quantity of segregation did not increase in the relevant years.

Within-school segregation, commonly referred to as "second-generation segregation," is thought to be as important as segregation across schools in inhibiting the educational opportunities of racial and ethnic minorities (Mickelson, 2001). Arguing against this hypothesis is evidence from Echenique, Fryer, and Kaufman (2006). They show, using the Spectral index to measure racial segregation of the school social networks of middle and high school students in the National Longitudinal Survey of Adolescent Health, that whether or not students are socially connected within schools has a substantively unimportant relationship with academic achievement.

The final explanation of how segregation can explain the trends in the achievement gap is more difficult to assess because of a lack of data on the effective price of segregation. It is 
plausible that schools in urban centers deteriorated relative to those in the suburbs during this time, and thus, the price of segregation increased. However, we cannot find any time series data that can serve as a reasonable proxy for school quality. Because of this, we are unable to make firm conclusions about the importance of segregation in explaining trends in the achievement gap. We know that the level of segregation has not changed substantially, but the consequences of that segregation may have become greater over time.

\section{Information-Based Models of Discrimination}

A second potential explanation for our set of time-series facts is that information-based discrimination (statistical or categorical in nature) leads to equilibria in which the net benefit of investment for those that are discriminated against is lower than for those who do not face discrimination, and this became more salient in the late 1980s and 1990s. To understand the explanatory power of these models, we outline the conceptual apparatus and main results in Coate and Loury (1993) and Fryer and Jackson (2008).

Coate and Loury (1993) build on the models of Arrow (1973) and Lundberg and Startz (1983) to develop a statistical discrimination model in which discrimination manifests itself in job assignments (such as Milgrom and Oster (1987)) rather than wages and includes an investment in human capital.

\section{Statistical Discrimination - The Basic Building Blocks}

Let there be a continuum of agents referred to as workers and a set of agents referred to as employers. Nature moves first and assigns a type to each worker. This type, denoted $c$, indicates each worker's cost of investing, where $c \in[\underline{c}, \bar{c}]$, such that $0<\underline{c}<\bar{c}<\infty$, with cumulative distribution function $G(\cdot)$. After observing their cost, workers makes an investment decision $q \in\{0,1\}$, where $q=1$ if the worker choose to become qualified and $q=0$ if not. Then, Nature distributes a signal $\theta \in[\underline{\theta}, \bar{\theta}]$ regarding the worker's investment decision. Let $F_{q}(\theta)$ denote the smooth and continuous cumulative distribution function of $\theta$ for a qualified worker and $F_{u}(\theta)$ is the cumulative distribution function of $\theta$ for unqualified workers, with related densities $f_{q}(\theta)$ and $f_{u}(\theta)$ respectively. Per usual, assume that these densities are strictly positive, continuous, bounded, and the ratio $\frac{f_{u}(\theta)}{f_{q}(\theta)}$ is decreasing in $\theta$ (monotone likelihood ratio property).

Next, the employer observes $\theta$ and makes a hiring decision $h \in\{0,1\}$ where $h=1$ if the employer decides to hire the worker and $h=0$ if not.

\section{Payoffs}


If the worker is hired, he receives a fixed payoff of $\omega-c$ if he chose to invest and $\omega$ if not, where $\omega>0$. The employer's net payoff for hiring a worker is $\chi_{q}>0$ if the worker is qualified and $-\chi_{u}<0$ if the worker is unqualified. The payoff to the employer for rejecting a worker is normalized to zero.

\section{Strategies}

A strategy for the worker specifies for each type whether he will invest. Namely, $I$ : $[\underline{c}, \bar{c}] \rightarrow\{0,1\}$ where $I$ is known as the worker's investment function. A strategy for the employer is an assignment decision. Formally, $A:[\underline{\theta}, \bar{\theta}] \rightarrow[0,1]$, where $A$ is known as the employer's function. Without loss of generality, the employer's strategy can be represented by a standard, $s^{*} \in[\underline{\theta}, \bar{\theta}]$, such that the employer hires the worker if $\theta \geq s^{*}$.

\section{Expected Payoffs}

Let $\pi$ denote the employer's prior probability that the worker is qualified. Expected payoffs for the employer are functions of her prior probability and the test score she observes. Given $\pi$ and observed $\theta$, she formulates a posterior probability $\Psi(\pi, \theta)$ that the worker is qualified. Using Bayes' rule, $\Psi(\pi, \theta) \equiv \frac{\pi f_{q}(\theta)}{\pi f_{q}(\theta)+(1-\pi) f_{u}(\theta)}$. The expected payoff for hiring a worker is then $\Psi(\pi, \theta) \chi_{q}-[1-\Psi(\pi, \theta)] \chi_{u}$

Conversely, the worker's expected payoff is a function of the threshold set by the employer and his cost. Expecting standard $s$, the worker's expected payoff is $\left[1-F_{q}(s)\right] \omega-c$ if he invests and $\left[1-F_{u}(s)\right] \omega$ if he does not invest.

\section{Equilibrium}

An equilibrium is a pair of functions $\left(I^{*}, A^{*}\right)$ such that each is a best response to the other. In any equilibrium, workers invest if and only if their cost is less than the net benefit: $c \leq\left[F_{u}(s)-F_{q}(s)\right] \omega \equiv \beta(s)$. The fraction of workers who invest in equilibrium is $G\left(\beta\left(s^{*}\right)\right)$. And, employers hire a worker with signal $\theta$ if and only if $\Psi(\pi, \theta) \chi_{q}-[1-\Psi(\pi, \theta)] \chi_{u}>$ $0 \Rightarrow\left(\frac{\pi}{1-\pi}\right) \geq\left(\frac{f_{u}(s)}{f_{q}(s)}\right)\left(\frac{\chi_{u}}{\chi_{q}}\right)$. An employers initial beliefs $\pi$ are self-confirming in that $\pi=$ $G\left(\beta\left(s^{*}\right)\right)$.

Coate and Loury (1993) show that multiple equilibria can exist. Figure 4 demonstrates the basic intuition. There are two stable equilibria. One equilibrium contains optimistic beliefs and relatively low standards, which induces workers to invest and confirms the employer's optimistic beliefs. A second equilibrium consists of relatively pessimistic beliefs which induce lower levels of investment from workers and this too confirms the employer's pessimistic views.

\section{Categorical Decision Making - Basic Building Blocks}


Let $C=\left\{C_{1}, \ldots, C_{n}\right\}$ denote a finite set of categories, $O$ represent a finite set of objects that are to be sorted, $m$ be the number of attributes possessed by an object, and $\theta: O \rightarrow$ $\{0,1\}^{m}$ denote the function, written as $\left(\theta_{1}(o), \ldots, \theta_{m}(o)\right)$, which describes the attributes that each object has.

Figure 4: Coate and Loury Multiple Equilibrium

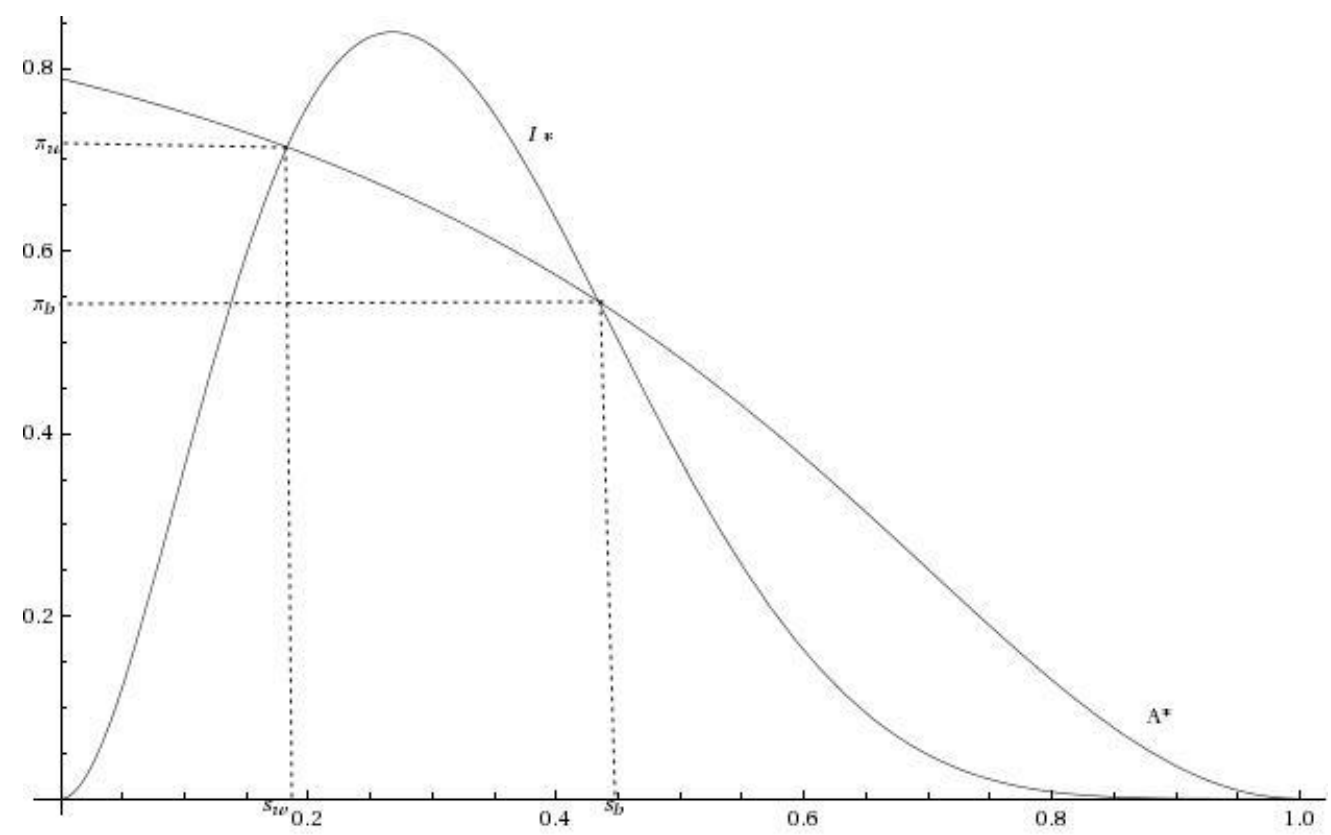

Once an object is encountered, then it is stored in memory by assigning it to a category. Let $f: O \rightarrow C$ denote the function that keeps track of the assignment of each object to a category, where $f(o)=C_{i}$ means that object $o$ has been assigned to category $C_{i}$.

Given some set of objects that have been categorized, $O$, and a categorization $f$, the decision-maker will find it useful to capture the essence of a category through a prototype. Fryer and Jackson (2008) define the prototype of a category to be the mean attribute vector:

$$
\bar{\theta}(O)=\frac{\sum_{o \in O} \theta(o)}{\#\{O\}} .
$$

The mean of a category $C_{i}$ under a categorization $f$ is then simply

$$
\bar{\theta}^{f}\left(C_{i}\right)=\bar{\theta}\left(\left\{o: f(o)=C_{i}\right\}\right)
$$

Now let us suppose that the decision maker faces an object and must choose an action $a$ 
from a set of actions $A$. The expected utility of taking action $a$ when faced with object $o$ is

$$
E U(a, o)=U(a, \bar{\theta}(f(o)) .
$$

That is, the decision maker calls upon past experiences as a guide for predicting future payoffs in a boundedly rational manner. The decision maker views an object only through the prototype of the category that the object is identified with.

Let us begin with an initial set of objects that our decision maker has interacted with in the past, $O$. The decision maker has categorized these according to some $f$. In some situations it will be useful for us to think about an "optimal" method of categorization. There are many possible ways to do this, and we pick an obvious one. We define an optimal categorization as categorizing past objects in a way to minimize the total sum (across objects) of within-category variance. In order to do this, we need to be explicit about how variation is measured.

Let $d$ be some measure of the distance between two vectors of attributes and let the variation of a group of objects simply be the total sum of distances from the mean:

$$
\operatorname{Var}(O)=\sum_{o \in O} d(\theta(o), \bar{\theta}(O)),
$$

The total sum of within category variance under a categorization $f$ is then simply summing the variation across the categories of objects:

$$
\operatorname{Var}(f, O)=\sum_{C_{i} \in C} \operatorname{Var}\left(\left\{o: f(o) \in C_{i}\right\}\right) .
$$

An optimal categorization function relative to $O$ is a categorization $f^{*}$ that minimizes $\operatorname{Var}(f, O) !^{6}$

Using the above framework, Fryer and Jackson (2008) present a series of results that partially characterize optimal categorizations; a general characterization is NP-hard. Taken together, their results suggest the following simple heuristic. Start by assigning groups to different categories until one is faced with more heterogeneous groups than categories. Then, group together the two that produce the smallest variation based on the groups currently faced, and continue in this manner until all objects are sorted. With small costs of reoptimization, a decision maker might continue down a myopic path of categorization with periodic reoptimizations. At a basic level, this heuristic algorithm for categorically

\footnotetext{
${ }^{6}$ There may be multiple solutions to this problem, but there is always at least one for any finite set of objects.
} 
processing information has deep intuition. Objects that are encountered less frequently (minority groups, e.g.) are sorted more coarsely in a decision maker's brain and less informed and nuanced decisions can be made regarding this set of objects.

\subsection{The Impact of Information-Based Discrimination on Skill Ac- quisition}

Models of statistical discrimination and categorization can potentially explain the achievement gap in levels. If $\pi_{b}^{*}<\pi_{w}^{*}$, as in Figure 4 , blacks invest less in skills and there is a resulting achievement gap. Similarly, if blacks are more coarsely categorized due to their small numbers in the population or segregation, their skills will not be equally rewarded and this too will lead to a skill gap.

To be consistent with the time series, one needs an exogenous shock in the late 1980s to a parameter in the model such as the beliefs, information technology, or frequency of social interactions. We have no good evidence either way on the plausibility of this assumption.

The theory seems to fall short, however, in explaining why blacks' investment decreases at precisely the time the return on investment was increasing. Both information-based discrimination models predict that blacks have a lower return on investment than whites. The empirical evidence, however, seems to point in the opposite direction. Table 1 presents the return to the Armed Forces Qualifying Test (AFQT) which is available in the National Longitudinal Survey of Youth 1979 and 1997. In both datasets, the return on investment in AFQT is as high, or higher, for blacks relative to whites (see also Neal and Johnson, 1996).

Table 1:

Racial Differences in the Return to AFQT

\begin{tabular}{|c|c|c|c|c|c|c|c|c|c|}
\hline & \multicolumn{4}{|c|}{ NLSY79 } & \multicolumn{5}{|c|}{ NLSY97 } \\
\hline & All Races & White & Black & Hispanic & All Races & White & Black & Hispanic & Mixed Race \\
\hline Black & $\begin{array}{l}-0.001 \\
(0.041)\end{array}$ & & & & $\begin{array}{l}-0.078 \\
(0.020)\end{array}$ & & & & \\
\hline Hispanic & $\begin{array}{c}0.078 \\
(0.036)\end{array}$ & & & & $\begin{array}{l}-0.001 \\
(0.017)\end{array}$ & & & & \\
\hline Mixed race & & & & & $\begin{array}{l}-0.038 \\
(0.076)\end{array}$ & & & & \\
\hline Age & $\begin{array}{c}0.009 \\
(0.016)\end{array}$ & $\begin{array}{l}-0.013 \\
(0.023)\end{array}$ & $\begin{array}{c}0.070 \\
(0.028)\end{array}$ & $\begin{array}{l}-0.023 \\
(0.036)\end{array}$ & $\begin{array}{c}0.051 \\
(0.004)\end{array}$ & $\begin{array}{c}0.059 \\
(0.006)\end{array}$ & $\begin{array}{c}0.045 \\
(0.008)\end{array}$ & $\begin{array}{c}0.037 \\
(0.009)\end{array}$ & $\begin{array}{c}0.023 \\
(0.053)\end{array}$ \\
\hline AFQT & $\begin{array}{c}0.273 \\
(0.019)\end{array}$ & $\begin{array}{c}0.257 \\
(0.026)\end{array}$ & $\begin{array}{c}0.286 \\
(0.039)\end{array}$ & $\begin{array}{c}0.313 \\
(0.031)\end{array}$ & $\begin{array}{c}0.099 \\
(0.010)\end{array}$ & $\begin{array}{c}0.108 \\
(0.012)\end{array}$ & $\begin{array}{c}0.152 \\
(0.018)\end{array}$ & $\begin{array}{c}0.094 \\
(0.019)\end{array}$ & $\begin{array}{c}0.083 \\
(0.117)\end{array}$ \\
\hline $\mathrm{AFQT}^{2}$ & $\begin{array}{c}0.034 \\
(0.017)\end{array}$ & $\begin{array}{c}0.040 \\
(0.023)\end{array}$ & $\begin{array}{c}0.021 \\
(0.035)\end{array}$ & $\begin{array}{c}0.062 \\
(0.028)\end{array}$ & $\begin{array}{l}-0.016 \\
(0.010)\end{array}$ & $\begin{array}{l}-0.021 \\
(0.012)\end{array}$ & $\begin{array}{l}-0.032 \\
(0.020)\end{array}$ & $\begin{array}{c}0.004 \\
(0.022)\end{array}$ & $\begin{array}{c}0.082 \\
(0.106)\end{array}$ \\
\hline Black x AFQT & $\begin{array}{c}0.013 \\
(0.044)\end{array}$ & & & & $\begin{array}{c}0.050 \\
(0.020)\end{array}$ & & & & \\
\hline Black x AFQT ${ }^{2}$ & $\begin{array}{r}-0.003 \\
(0.039) \\
\end{array}$ & & & & $\begin{array}{c}0.002 \\
(0.020) \\
\end{array}$ & & & & \\
\hline Obs. & 2211 & 1134 & 652 & 425 & 6482 & 3419 & 1598 & 1410 & 55 \\
\hline$R^{2}$ & 0.165 & 0.137 & 0.128 & 0.162 & 0.068 & 0.053 & 0.078 & 0.032 & 0.049 \\
\hline
\end{tabular}




\section{Peer Dynamics}

Our third class of models is a formal representation of a peculiar peer externality referred to as peer pressure or, more casually, 'acting white.' Economists and sociologists have argued that differences in academic achievement are the result of negative peer interactions or spillovers which are manifested in a particularly insidious form: black peers/communities impose costs on their members who try to 'act white' (Fordham and Ogbu, 1986; Fordham, 1996; Corwin, 2001; Suskind, 1998) 7 Individuals exposed to these social interactions have disincentives to invest in particular behaviors (i.e. education or proper speech) due to the fact that they may be rejected by their social peer group.

In what follows, we present a simple model of peer pressure based on insights from AustenSmith and Fryer (2005) and Fryer (2007). The key idea is that an individual's educational investment is a signal, both to potential employers about the individual's productivity and to peers about the individual's social compatibility. Employers are free to adjust wages continuously in an individual's signaled productivity; the peer group simply makes a binary decision regarding whether the individual is deemed acceptable or not. So, although it is assumed that employers have no direct interest in the individual's social status and that peers have no direct interests in the individual's productivity, the equilibrium consequence of twoaudience signaling with a common decision is that a subset of productive types underinvest in education relative to the situation without any peers to impress. The following model captures this intuition.

\section{The Basic Building Blocks}

Let there be a continuum of individuals with unit mass, a finite set of firms, and a (suitably anthropomorphized) peer group. There are two discrete stages of an individual's life: "school years" and "employment years," denoted $\tau \in\{0,1\}$. Nature moves first and distributes an innate ability, $\theta$, to each student according to a smooth common knowledge cumulative distribution function (CDF) F. Abilities, once disseminated, are fixed. An individual is endowed with one unit of non-storable time in each period, the allocation of which is common knowledge.

At the start of each period, an individual's stage $\tau$ time allocation problem is influenced by whether or not she is an accepted member of her peer group. Peer groups are valued because, other things equal, leisure time spent in the group is more enjoyable than leisure time spent outside the group. If an individual is not an accepted member, then she makes decisions without reference to the group. If she is an accepted group member, then she may be called upon to make some observable time contribution to the group. That is, in

\footnotetext{
${ }^{7}$ There is no consensus on this view, however. A discussion follows in section 4.1.
} 
each stage $\tau$, Nature chooses a required time contribution $\kappa_{\tau} \in[0, \bar{\kappa}), 0<\bar{\kappa}<1$, from the individual to the group, according to a smooth common knowledge CDF $G_{\tau}\left(\kappa_{\tau}\right)$. We assume the school year contribution is expected to be no greater than the post-school year contribution.

In the "school years," individuals allocate effort among leisure, group commitments, and a once-and-for-all investment in education, $s \in[0,1]$. The cost of investing $s$ for an individual with ability $\theta$ is denoted $c(s, \theta)]^{8}$ The cost function is assumed to be strictly increasing and convex in education, to be strictly decreasing in innate ability and to satisfy the singlecrossing property. To ensure that all ability types choose interior education levels, we further assume that $\lim _{s \rightarrow 0} c_{s}(s, \cdot)=0$ and $\lim _{s \rightarrow 1} c_{s}(s, \cdot)=\infty$.

At the end of the school years, an individual's education level is fixed and firms choose wage offers to maximize expected profit. Because firms do not observe an individual's innate ability, the wage offered to any potential employee is that individual's expected marginal product conditional on her observed schooling. For simplicity, assume that individuals are paid a wage equal to their expected marginal product, $\omega(s) \geq 0$, and (where appropriate) specify the firms' responses to any out of equilibrium action by an individual.

Let $\alpha_{\tau} \in 0,1$ denote whether the individual is rejected $\left(\alpha_{\tau}=0\right)$ or accepted $\left(\alpha_{\tau}=1\right)$ by his or her peer group in $\tau$. If an individual is rejected by the group during the school years, she cannot be accepted in the post-school years; however, an individual accepted by the group in the school years may be rejected in the post-school years ${ }^{9}$ Let $u\left(l_{\tau} \mid \alpha_{\tau}\right)$ be the individual's stage $\tau$ payoff from leisure $l_{\tau} \in[0,1]$, conditional on the group's decision. If an individual is an accepted group member in some $\tau$ and is asked to make a contribution $\kappa_{\tau}$, let $\delta_{\tau} \in\{0,1\}$ denote an individual's decision on whether or not to comply (respectively, $\delta_{\tau}=1$ or $\left.\delta_{\tau}=0\right)$. Thus, an individual's stage 0 payoff from choosing $\delta_{0}$, given the individual's innate ability, school year education decision, and required contribution $\kappa_{0}$ can be written as: $u\left(1-s-\alpha_{0} \delta_{0} \kappa_{0} \mid \alpha_{0}\right)-c(s, \theta)$. Assume $u(l \mid \cdot)$ is twice differentiable concave, increasing in $l$ over the range $(0,1)$, and no leisure is worthless irrespective of group acceptance. Further, we assume that both total and marginal values from consuming any strictly positive amount of leisure are greater as an accepted group member than otherwise.

At the beginning of the employment years, the group makes another acceptance decision, and Nature reveals an individual's post-school years time commitment to the group, $\kappa_{1}$. Then, each individual decides whether or not to contribute to the group, and makes workforce effort decision $e \in[0,1]$. Any student who is accepted by the group and contributes in the post-school years receives a lifetime utility benefit $\beta 10$ The employment years payoff

\footnotetext{
${ }^{8}$ This is in addition to the direct opportunity cost of effort used for education in the school years.

${ }^{9}$ This is without any loss of generality (Austen-Smith and Fryer, 2003).

${ }^{10}$ In the infinite horizon version of the model (Austen-Smith and Fryer, 2003), the value $\beta$ is explicitly
} 
can be written as: $u\left(1-e-\alpha_{1} \delta_{1} \kappa_{1} \mid \alpha_{1}\right)+e \omega(s)+\rho \alpha_{1} \delta_{1} \beta$, where $\rho \in(0,1)$ is a standard discount factor.

Suppose an individual is accepted by his peers in the school years. At the beginning of the employment years, the group decides whether to accept or reject the individual. Then, Nature randomly chooses the group contribution, $\kappa_{1}$, required of each individual and they decide whether to make the contribution. The realization and the individual's decision are observed by the group. Let $\alpha_{\tau} \psi\left(\delta_{\tau}, \kappa_{\tau}\right)$ be the stage $\tau$ payoff to the group from action $\alpha_{\tau}$, given the individual makes decision $\delta_{\tau}$ when the required contribution is $\kappa_{\tau}$, where for all $\kappa_{\tau} \geq 0, \psi\left(1, \kappa_{\tau}\right)>\psi\left(0, \kappa_{\tau}\right)$. The key feature of the group's payoffs is that the group is strictly worse off having accepted an individual who chooses not to make her required contribution than it would be were such an individual rejected.

Figure 5: Non-Existence of Fully Separating Equilibria

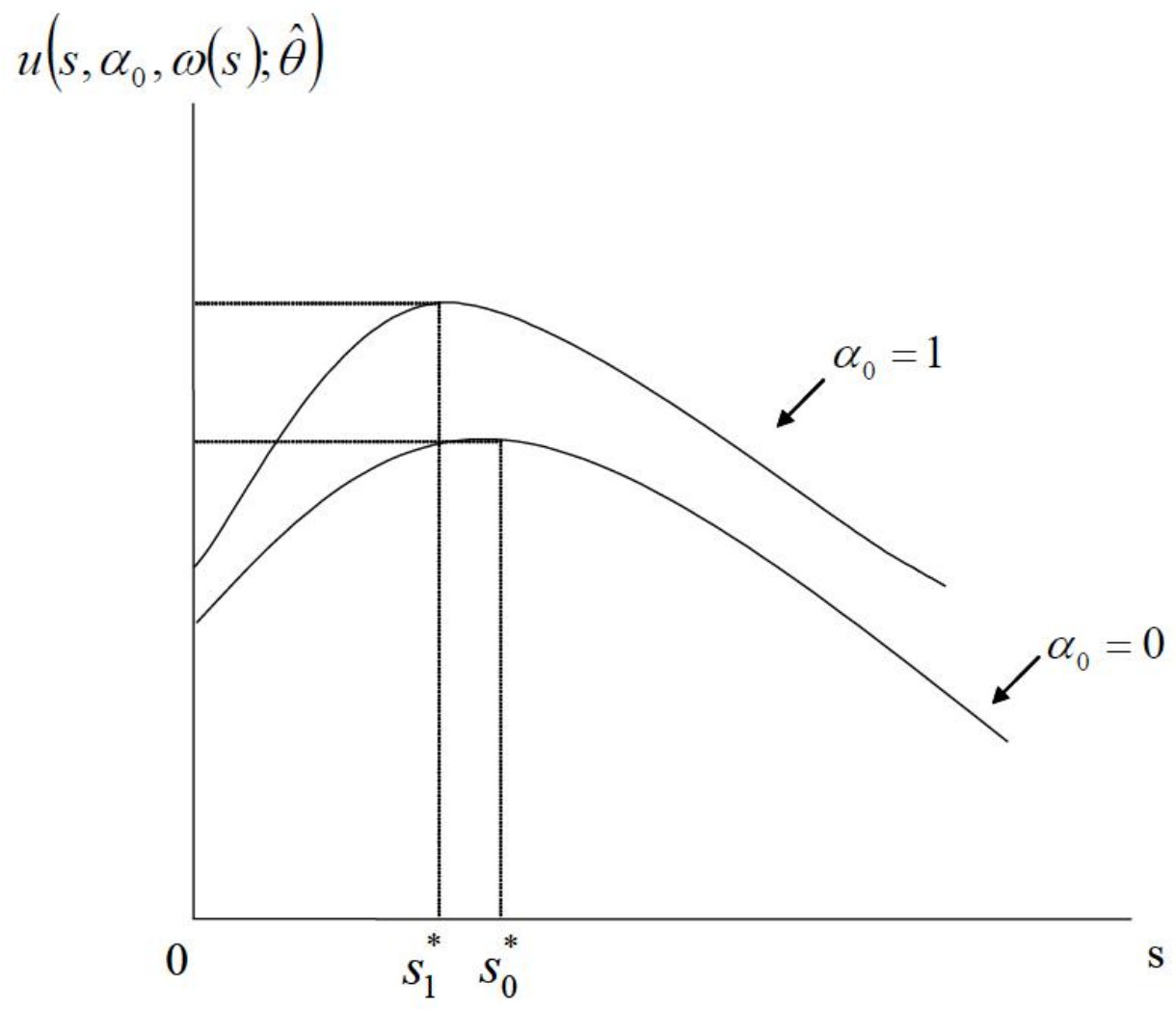

Solving the preceding model yields three results. First, no equilibria exist in which all types adopt distinct education choices; all equilibria must involve some pooling. This result

derived as an equilibrium payoff to a repeated interaction game between the individual and the group. As such, it depends on school years decisions, among others. In the two-period model, it is enough for there to be some reason for the individual to contribute in the post-school years if required to do so. 
is illustrated in Figure 5, which depicts the net utility accruing to a type $\hat{\theta}$ individual. As shown in the figure, at any given educational investment level, $s$, the individual's net payoff is strictly greater being accepted than being rejected by the group, and further, in each case the net payoff is strictly quasi-concave in educational effort with an interior maximum.

Second and most interesting, after application of a standard belief-based equilibrium refinement (the D1 criterion), all equilibria involve a partition of individual abilities into at most three intervals, which is depicted in Figure 6. A (possibly empty) set of the lowest ability types $\left(\theta<\theta_{1}\right)$ and the set of highest ability types $\left(\theta>\theta^{*}\right)$ reveal themselves through a separating education strategy; ability types in the middle interval $\left(\theta \in\left[\theta_{1}, \theta^{*}\right]\right)$ pool on a common education level. Only types in the lower intervals are accepted by the group. It is worth emphasizing that nothing is built into the model that requires accepted types to adopt a common educational investment; it is an equilibrium outcome.

The two-audience signaling model has two clear predictions: racial differences in the relationship between group acceptance and academic achievement will exist and these differences will tend to be exacerbated in environments with more interracial contact and increased mobility. Thus, contrary to models of information-based discrimination, one might expect less investment in these models of peer dynamics when there is a wage premium. The next step is to get a sense of the potential magnitudes of these theoretical predictions.

Figure 6: D1 Equilibria in the Two-Audience Signaling Model
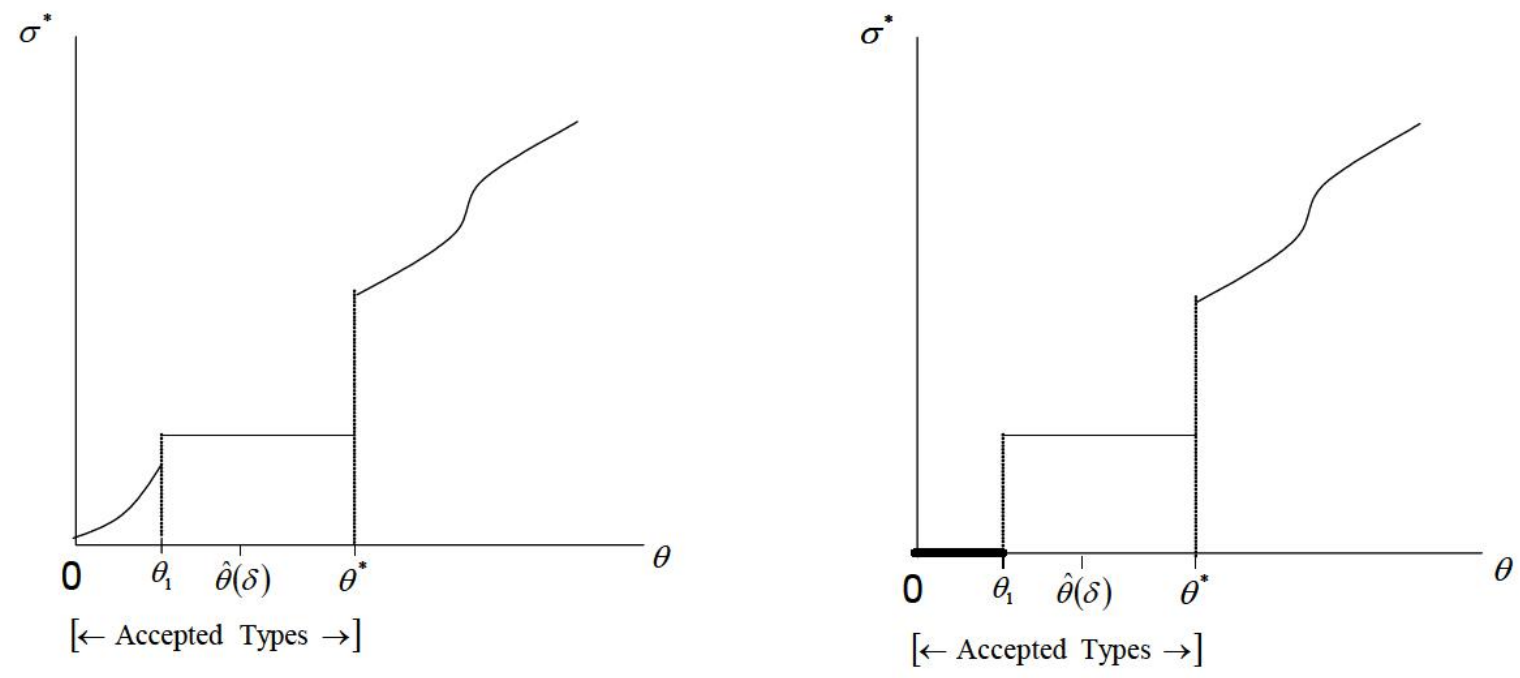


\subsection{The Potential Impact of 'Acting White' on Achievement}

There is a small literature on the existence of 'acting white' that includes both qualitative and quantitative analysis in sociology, economics, and policy studies. Two of the most important papers in this literature are Fordham and Ogbu (1986) and Fordham (1996), which argue for the prevalence of an oppositional culture among black youth that eschew behaviors traditionally seen as the prerogative for whites. Their hypothesis states that the observed disparity between blacks and whites stems from the following factors: (1) white people provide them with inferior schooling and treat them differently in school; (2) by imposing a job ceiling, white people fail to reward them adequately for their academic achievement in adult life; and (3) black Americans develop coping devices which, in turn, further limit their striving for academic success ${ }^{11}$ In other words, a major reason that black students do not do well in school is that they experience inordinate ambivalence and affective dissonance in regard to academic effort and success ${ }^{12}$ This dilemma between racial authenticity and achievement has been documented in many ethnographies and the popular media 13

There is an apparent conflict between the ethnographic evidence on 'acting white' and two nationally representative studies that seemingly find no justification for the oppositional culture hypothesis - attempting to dismiss 'acting white' as nothing more than an urban legend (Ainsworth-Darnell and Downey, 1998; Cook and Ludwig, 1998). Cook and Ludwig (1998) ask three questions: (1) Do African-American adolescents report greater alienation from school than non-Hispanic whites? (2) Does academic success lead to social ostracism among black adolescents? (3) Do the social costs or benefits of academic success differ by race? For each question, their answer based on analysis of the National Educational Longitudinal Survey (NELS) - a nationally representative sample of 24,599 students who were in eighth grade in 1988 - is "apparently not."

\footnotetext{
${ }^{11}$ Fordham and Ogbu (1986) suggest the problem arose partly because white Americans traditionally refused to acknowledge that black Americans were capable of intellectual achievement, and partly because black Americans subsequently began to doubt their own intellectual ability, began to define academic success as white people's prerogative, and began to discourage their peers, perhaps unconsciously, from emulating white people in striving for academic success.

${ }^{12}$ Generally, there are large literatures concerning group influences on individual decision-making in sociology and social psychology, yet efforts to develop more formal models addressing how such influences affect economic decisions in general, let alone with regard to education and investment in human capital, are relatively new. And within the formal literature, most of the work is devoted to understanding the economic implications of (more or less) given social norms: recent examples include Akerlof $(1976,1980)$, Bernheim (1994), Lindbeck, Nyberg, and Weibull (1999), and Cole, Mailath, and Postlewaite (1992). While much of this literature bears in some way on the issue here, none of it directly considers the role of peer pressure on human capital formation.

${ }^{13}$ For recent work on the prevalence of 'acting white' among blacks, see Corwin (2001), Fordham (1991), Ogbu and Davis (2003), or Suskind (1998). One can also conduct a Lexis-Nexis search of major newspapers, which will yield scads of articles.
} 
Fryer and Torelli (forthcoming) uses the National Longitudinal Study of Adolescent Health (Add Health) data set, which is a nationally representative sample of 90,118 students entering grades 7 through 12 in the 1994-1995 academic year. The key feature of the Add Health data is the detailed information regarding friendship associations in schools. All students contained in the in-school survey were asked, "List your closest male/female friends. List your best male/female friend first, then your next best friend, and so on." Students were allowed to list as many as five friends from either sex. Each friend can be linked in the data and the full range of covariates in the in-school survey (race, gender, grade point average, etc.) can be gleaned from each friend.

To circumvent some of the problems inherent in self-reported popularity measures such as those contained in NELS, Fryer and Torelli (forthcoming) construct an index of social status. For each student the index measures the number of same-race friends within her school, weighted by the social status of each friend. The index is implemented using the detailed information on friendship networks above.

Figure 7: Spectral Popularity and Grades by Race, Raw Data (Add Health)

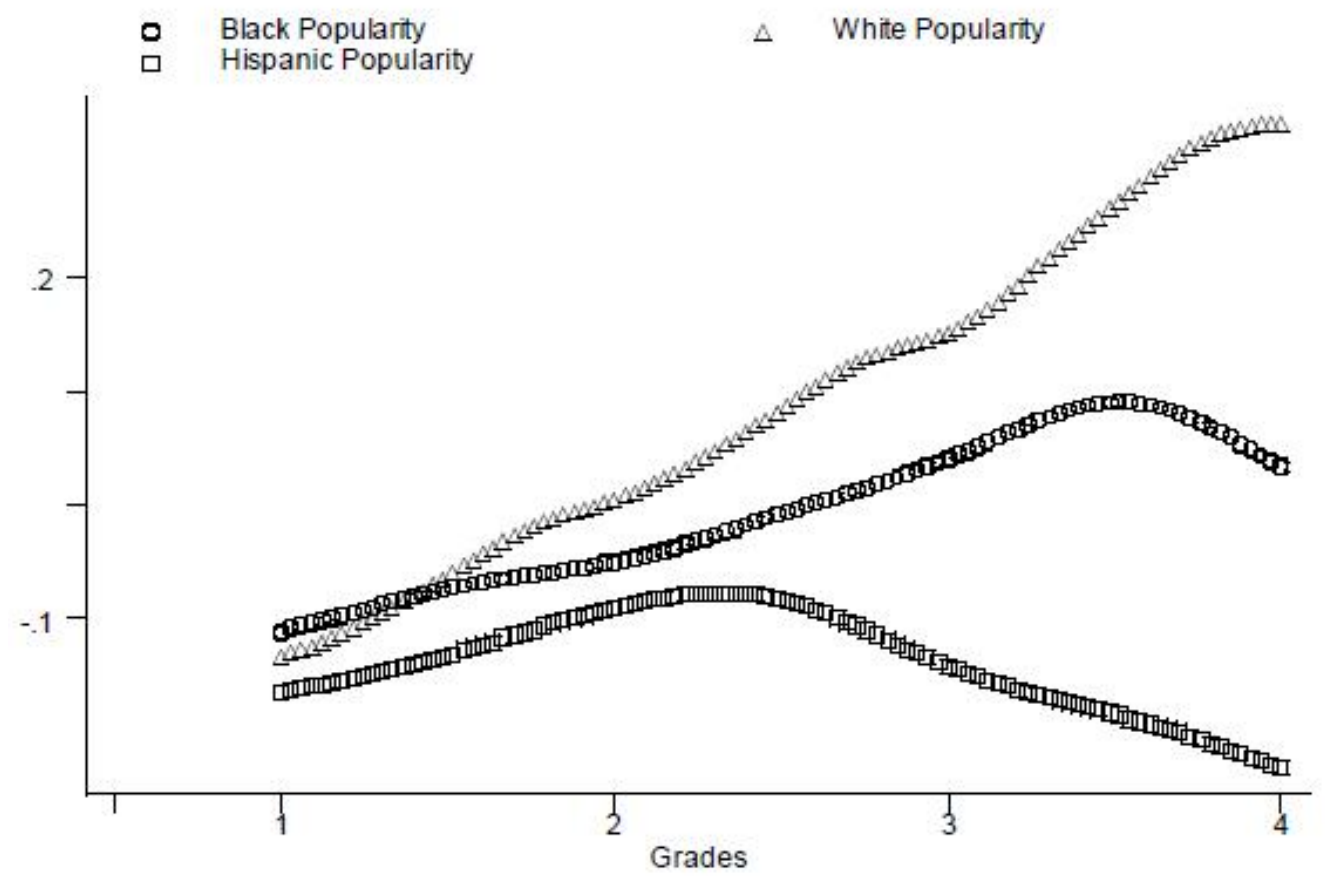

Figure 7 presents the relationship between social status and grades among whites, blacks, and Hispanics in the raw data. At low grade point averages, there is little difference among racial groups in the relationship between social status and grades; blacks are more popular 
than whites. At roughly a 2.5 GPA (an even mix of B's and C's) racial differences start to emerge. Hispanic students lose social status at an alarming rate after this cut-off - while blacks and whites continue to garner friends as their grades increase; the white slope is steeper. Black social status peaks at a grade point average of roughly 3.48 (an even mix of A's and B's) and turns down afterward. Blacks with straight A's are as popular as blacks with a 2.9 GPA. Whites continue to gain social status as their grades increase.

Fryer and Torelli (forthcoming) explore the sensitivity of these results to alternative empirical specification and myriad subsamples of the data. For instance, one of the biggest worries with the results presented thus far is that they implicitly assume that higher grades cause lower popularity. It is certainly plausible that high popularity causes lower grades through a simple time constraint or other mechanism. Using an instrument for popularity - a student's physical attractiveness - Fryer and Torelli (forthcoming) argue that the causal arrow is in the expected direction.

The most surprising finding from this exercise is how the coefficient on 'acting white' varies in arenas with more or less interracial contact. Partitioning the sample of schools in several ways demonstrates this: high versus low segregation, schools where blacks and whites are the simple majority and schools that are 80 percent black versus those that are 20 percent black. Remarkably, schools that are less than 20 percent black have the largest 'acting white' effect for blacks and Hispanics. In schools that are 80 percent black or greater, the coefficient on grades is large and negative and the coefficient on black interacted with grades is large, positive, and imprecisely measured. A joint significance test confirms that one cannot distinguish between the coefficients on grades and black* grades in the full sample and schools that are greater than 80 percent black. We can be confident, however, that the 'acting white' coefficients are statistically different between schools that are less than 20 percent black and those that are greater than 80 percent. Similarly, blacks in more segregated schools incur less of a tradeoff between social status and achievement. The coefficient on the 'acting white' term is twice as large in schools that are above the median in terms of segregation (-0.055 compared to -0.136). Among high-achievers, the differences are starker $(-0.144$ and -0.536$)$ [not shown in tabular form].

To supplement this analysis, we also depict racial differences between the number of friends a student has in a school and their classroom grades using data collected from all middle schools in Washington, DC - the same city which Fordham and Ogbu (1986) collected their qualitative data. We used the same questionnaire administered in Add Health to assess the social networks of students in schools. We then linked this data to administrative files kept by the school district which contains student grades, test scores, and so on. 
Figure 8: Popularity and Grades by Race, Raw Data (DC District)

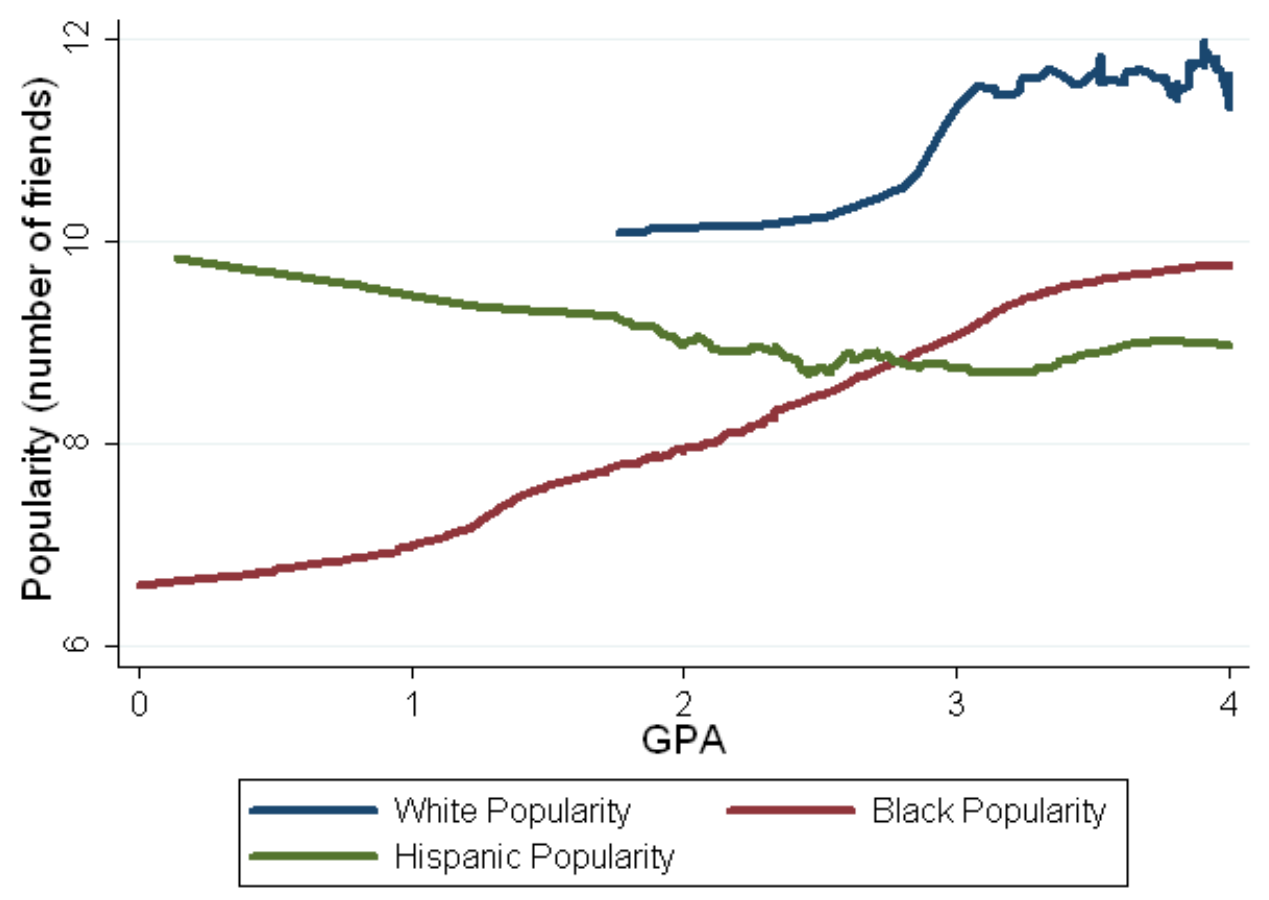

Figure 8 is similar to figure 7 , but the sample is all Washington, DC, public middle schools. Hispanic popularity decreases monotonically with their grade point average - higher grades are associated with lower popularity. Popularity and grades are positively correlated for white students until a grade point average of roughly 3. That is, B students and A students garner the same high level of popularity in school. Black popularity increases monotonically from very low grades to straight A students. These data are consistent with the results in Fryer and Torelli (forthcoming) - no racial differences in the relationship between social status and achievement in majority black schools.

\section{How Do We Reconcile Differences in NELS and Add Health?}

There are three ways to reconcile the starkly different conclusions in Cook and Ludwig (1997) and Fryer and Torelli (forthcoming). First, the NELS contains a question that asks if the student "thinks others see him/her as popular." The answer choices are: 'not at all,' 'somewhat,' or 'very'; over 80 percent of the respondents categorized themselves as 'somewhat' or 'very' popular. The popularity index in Fryer and Torelli (forthcoming) is a continuous measure. Second, Cook and Ludwig (1997) also use two dichotomous achievement measures: (1) whether the student earns "mostly A's in math"; and whether the student is in the honor society. Fryer and Torelli (forthcoming) use a continuous measure of GPA from 
0 to 4.0. A third possibility is that Add Health and NELS are just different data sets with different sampling protocols and yield different conclusions.

Fryer and Torelli (forthcoming) show that using dichotomous or other measures of popularity in Add Health yields the same results, but restructuring the academic achievement measure to be dichotomous (mostly A's, e.g.) as in Cook and Ludwig (1997) the racial differences between popularity and achievement in Add Health disappear. Further, using a continuous measure of grade point average (gleaned from transcript files) in the NELS provides similar results to those in Fryer and Torelli (forthcoming). Thus, the stark differences in the empirical literature on 'acting white' are simply due to the fact that dichotomous measures of achievement mask important differences between racial groups in the relationship between social status and academic achievement.

\section{How Important is 'Acting White' in Explaining Trends in the Racial Achievement Gap?}

We cannot even hazard a guess. The comparative statics of the theoretical models are consistent with the trends, but it is unclear whether the empirical work thus far even captures the important elements of the phenomenon. Thus, we echo Ferguson (1998) on the importance of collecting new data that more accurately measures the social interactions of students and the effort that students put into their schoolwork. To date, data sets available to researchers do not measure the behaviors that are most indicative of peer dynamics.

\section{$5 \quad$ Identity}

Our final model uses identity - a person's sense of self - in economic decision making ala Akerlof and Kranton (2000). In their proposed utility function, identity is based on social categories, $C$. Each person $j$ has an assignment of people to these categories, $C_{j}$, so that each person has a conception of her own categories and that of all other people. Prescriptions $P$ indicate the behavior appropriate for people in different social categories in different situations. The prescriptions may also describe an ideal for each category in terms of physical characteristics and other attributes. Categories may also have higher or lower social status. Akerlof and Kranton (2000) use the word identity to describe both a person's self-image as well as her assigned categories.

Consider the following utility function: $U_{j}=U_{j}\left(a_{j}, a_{-j}, I_{j}\right)$. Utility depends on $j$ 's identity or self-image, $I_{j}$, as well as on the usual vectors of $j$ 's actions, $a_{j}$ and the actions of others, $a_{-j}$. Since $a_{j}$ and $a_{-j}$ determine $j$ 's consumption of goods and services, these arguments and $U_{j}(\cdot)$ are sufficient to capture the standard economics of own actions and externalities. 
Let $I_{j}=I_{j}\left(a_{j}, a_{-j} ; c_{j}, \epsilon_{j}, P\right)$ denote person $j$ 's identity, which depends on $j$ 's assigned social categories $c_{j}$. The social status of a category is given by the function $I_{j}(\cdot)$, and a person assigned a category with higher social status may enjoy an enhanced self-image. Identity further depends on the extent to which $j$ 's own given characteristics, $\epsilon_{j}$, match the ideal of $j$ 's assigned category, indicated by the prescriptions $P$. Finally, identity depends on the extent to which $j$ 's own and others' actions correspond to prescribed behavior indicated by $P$. Increases or decreases in utility that derive from $I_{j}$ are gains or losses in identity. In the simplest case, an individual $j$ chooses actions to maximize utility $U_{j}$, taking as given $c_{j}$, $\epsilon_{j}$, and $P$ and the actions of others.

\subsection{Interpreting the data through the lens of an Identity Model}

An identity model such as Akerlof and Kranton (2000) can potentially explain our time-series data on the racial achievement gap if there was a shift in culture or identity prescriptions in the late 1980s and 1990s. A primary obstacle to the study of culture and identity has been the lack of quantitative measures. Using data that cover every child born in California over a period of four decades (1961-2000), Fryer and Levitt (2004) document stark differences between black and white name choices. More than forty percent of the black girls born in California in recent years received a name that not one of the roughly 100,000 white girls born in California in that year was given (Fryer and Levitt, 2004). Even among popular names, racial patterns are pronounced. Names such as DeShawn, Tyrone, Reginald, Shanice, Precious, Kiara, and Deja are quite popular among blacks, but virtually unheard of for whites. Connor, Cody, Jake, Molly, Emily, Abigail, and Caitlin are distinctively white names. Each of those names appears in at least 2,000 cases, with less than two percent of recipients black. Overall, black choices of first names differ substantially more from whites than do the names chosen by native born Hispanics and Asians.

Surprisingly, the time series pattern of black first names follows a similar pattern to the test scores in Figure 1. In the 1960s, the differences in name choices between blacks and whites were relatively small, and factors that predict distinctively black names in later years (single mothers, racially isolated neighborhoods, etc.) have much lower explanatory power in the 1960's. At that time, blacks who lived in highly racially segregated neighborhoods adopted names that were almost indistinguishable from blacks in more integrated neighborhoods. Within a seven-year period in the early 1970's, however, a profound shift in naming conventions took place, especially among blacks in racially isolated neighborhoods. The median black female in a segregated area went from receiving a name that was twice as likely to be given to blacks as whites to a name that was more than twenty times as likely to be given 
to blacks. Black male names moved in the same direction, but the shift was less pronounced. Among a subset of blacks, encompassing about one-fourth of blacks overall and one-half of those in predominantly white neighborhoods, name choices actually became more similar to those of whites during this period.

Figure 9: Changes in Black Naming Patterns by Racial Composition of Neighborhood and by Quartile of Black Name Index
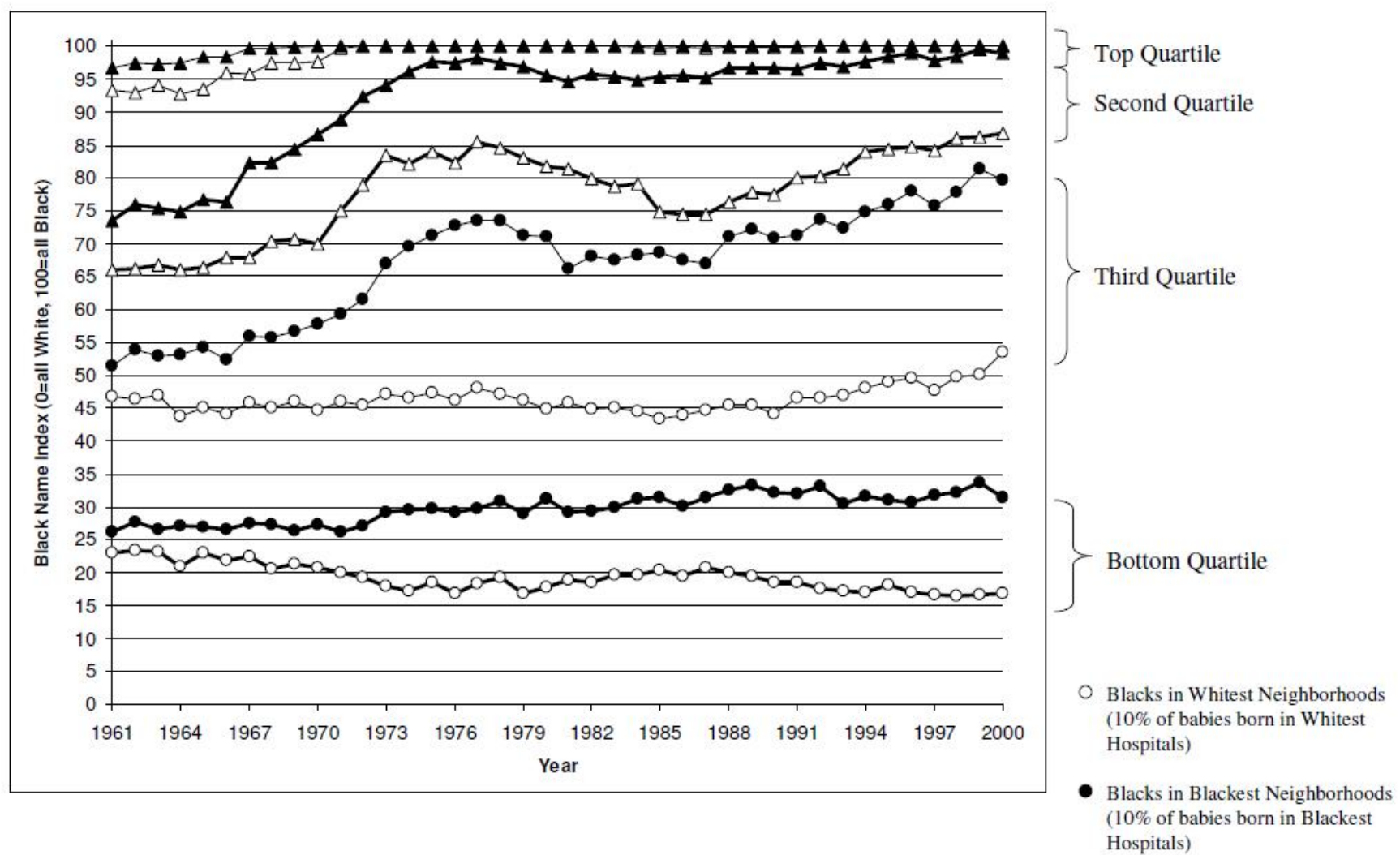

For children born in each year between 1961 and 2000, Fryer and Levitt (2004) compute a black name index (BNI) - the share of individuals with a given name that are black - and then rank order the blacks in their sample according to how black each newborn's name is. Figure 9 presents the mean BNI by year for each of the four quartiles of the distribution. The top quartile is very close to 100 throughout the entire time period (i.e. almost one-quarter of blacks had names virtually never given to whites throughout the sample) and thus exhibits little time-series variation. For the other three quartiles, black naming patterns were largely stable throughout most of the 1960s. Beginning in the late 1960s, the second quartile from the top experiences a sharp rise in how black the name choices are. Between 1968 and 1977, the mean BNI within this quartile goes from roughly 75 (meaning the name was three times 
as likely to be given to a black baby as a white baby) to almost 95 (15 times more likely to be given to a black baby). The third quartile also rises over that time period, but not as sharply, and then increases more dramatically over the period 1985-2000. The bottom quartile, in contrast, remains almost unchanged throughout the sample period.

Whether or not the substantial increases in black naming patterns in the third quartile between 1985 and 2000 are indicative of a large cultural shift (similar to the Black Power Movement in the late 1960s) is unknown. The late 1990s was a period in which rap music gained enormous popularity and Afrocentric curriculum spread through schools (Au, 2005; Thernstrom, 1992). Indeed, some have argued that rap music is the reason for the decline in black test scores in the late 1980s (Ferguson, 2001). The impact of hip-hop music on the racial achievement gap is an important question for which we have very little data. Yet, underlying forces that both popularized hip-hop and created a rise in Afrocentrism during the late 1980s may be associated with a shock to the identity prescriptions of black adolescents. If true, this has the potential to explain the trends. Much more testing and data are needed before one can make firm conclusions.

\section{Conclusion}

One of the biggest puzzles in the analysis of racial inequality is why black and white academic achievement diverges at a time when the price of skills is increasing. In this chapter, we have explored the extent to which models of segregation, information-based discrimination, peer dynamics and identity can explain this set of facts.

Segregation is an unlikely answer unless one finds evidence that suggests the price of segregation changed drastically over the relevant time period. The level of segregation has been decreasing in America since the 1940s (Cutler, Glaeser, and Vigdor, 1999). Models of information-based discrimination are also unlikely to explain the trends in the racial achievement gap. This class of models has the troubling feature that the return on investment is lower for the group who is discriminated against. Yet, data suggest the opposite.

Models of peer dynamics and identity - both relatively new to the field of social economics - have the potential to explain the data. Their differences are subtle: the identity model depends on a shift in preferences which eschews achievement; a peer dynamic framework predicts that achievement and social mobility will be negatively correlated. Further data and refinement of these models are needed to eventually solve this important puzzle. 


\section{References}

[1] Ainsworth-Darnell, James and Douglas Downey, "Assessing the Oppositional Culture Explanation for Racial/Ethnic Differences in School Performance," American Sociological Review, LXIII (1998), 536-553.

[2] Akerlof, George, "The Economics of the Rat Race and Other Woeful Tales," Quarterly Journal Economics, XC (1976), 599-617.

[3] Akerlof, George, "A Theory of Social Custom of Which Unemployment May Be One Consequence," Quarterly Journal Economics, XCIV (1980), 599-617.

[4] Akerlof, George and Rachel Kranton, "Economics and Identity," Quarterly Journal of Economics, CXV (2000), 715-753.

[5] Almond, Douglas, Kenneth Chay, and Michael Greenstone, "Civil Rights, the War on Poverty, and Black-White Convergence in Infant Mortality in Mississippi," mimeo, Massachusetts Institute of Technology, Department of Economics, (2003).

[6] Arrow, Kenneth J., "The Theory of Discrimination," In Orley Ashenfelter and Albert Rees, eds., Discrimination in Labor Markets. (Princeton, NJ: Princeton University Press, 1973).

[7] Atkinson, Anthony, "On the measurement of inequality," Journal of Economic Theory, II (1970), 244-263.

[8] Au, Wayne, "Rap Music's Discursive Battle with Education," The Journal of Negro Education, LXXIV (2005), 210-220.

[9] Austen-Smith, David and Roland G. Fryer, Jr., "The Economics of 'Acting White.'" NBER Working Paper No. 9904, (2003).

[10] Austen-Smith, David and Roland G. Fryer, Jr., "An Economic Analysis of 'Acting White'," Quarterly Journal of Economics, CXX (2005), 551-583.

[11] Bernheim, Douglas, "A Theory of Conformity," Journal of Political Economy, CII (1994), 841-877.

[12] Blau, Peter, Inequality and Heterogeneity: A Primitive Theory of Social Structure. (New York, NY: Free Press, 1977) 
[13] Borjas, George, "Ethnicity, Neighborhoods, and Human-Capital Externalities," American Economic Review, LXXXV (1995), 365-390.

[14] Campbell, Jay R., Catherine M. Hombo, and John Mazzeo, NAEP 1999 Trends in Academic Progress: Three Decades of Student Performance, Washington, DC: National Center for Education Statistics, (2000).

[15] Card, David and Jesse Rothstein, "Racial segregation and the black-white test score gap," Journal of Public Economics, XCI (2007), 2158-2184.

[16] Case, Anne and Lawrence Katz, "The Company You Keep: The Effects of Family and Neighborhood on Disadvantaged Youths." NBER Working Paper No. 3705, (1991).

[17] Coate, Stephen and Glenn C. Loury, "Will Affirmative-Action Policies Eliminate Negative Stereotypes?," American Economic Review, LXXXIII (1993), 1220-1240.

[18] Cole, Harold, George Mailath, and Andrew Postlewaite, "Social Norms, Savings Behavior and Growth," Journal of Political Economy, C (1992), 1092-1225.

[19] Collins, Chiquita and David R. Williams, "Segregation and Mortality: The Deadly Effects of Racism?," Sociological Forum, XIV (1999), 495-523.

[20] Cook, Philip J. and Jens Ludwig, "Weighing the 'Burden of "Acting White"': Are There Race Differences in Attitudes toward Education?," Journal of Policy Analysis and Management, XVI (1997), 256-278.

[21] Cook, Phillip and Jens Ludwig, "The Burden of 'Acting White': Do Black Adolescents Disparage Academic Achievement?" In Christopher Jenks and Meredith Phillips, eds., The Black-White Test Score Gap. (Washington, DC: Brookings Press, 1998).

[22] Corwin, Miles, And Still We Rise: The Trials and Triumphs of Twelve Gifted Inner-City Students. (New York: Harper Collins, 2001).

[23] Cowgill, Donald and Mary Cowgill, "An Index of Segregation Based on Block Statistics," American Sociological Review, XVI (1951), 825-831.

[24] Crain, Robert and Jack Strauss, "School Desegregation and Black Occupational Attainments: Results from a Long-Term Experiment," Center for Social Organization of Schools, Johns Hopkins University, (1985). 
[25] Crain, Robert, and Rita Mahard, "Minority Achievement: Policy Implications of Research," In Willis D. Hawley, ed., Effective School Desegregation: Equity, Quality, and Feasibility. (Beverly Hills, CA: Sage Publications, 1981).

[26] Cutler, David, and Edward Glaeser, "Are Ghettos Good or Bad?," Quarterly Journal of Economics, CXII (1997), 827-872.

[27] Cutler, David M., Edward L. Glaeser, and Jacob L. Vigdor, "The Rise and Decline of the American Ghetto," Journal of Political Economy, CVII (1999), 455-506.

[28] Echenique, Federico and Roland Fryer, "A Measure of Segregation Based on Social Interactions," Quarterly Journal of Economics, CXXII (2007), 441-485.

[29] Echenique, Federico, Roland Fryer, and Alex Kaufman, "Is School Segregation Good or Bad?, " American Economic Review, XCVI (2006), 265-269.

[30] Ferguson, Ronald, "Can Schools Narrow the Black-White Test Score Gap?" In Christopher Jencks and Meredith Phillips, eds., The Black-White Test Score Gap. (Washington, DC: Press, 1998).

[31] Ferguson, Ronald, "A Diagnostic Analysis of Black-White GPA Disparities in Shaker Heights, Ohio," Brooking Papers on Education Policy, (2001), 347-414.

[32] Fordham, Signithia, "Racelessness in Private Schools: Should We Deconstruct the Racial and Cultural Identity of African-American Students?," Teachers College Record, XCII (1991), 470-484.

[33] Fordham, Signithia, Blacked Out: Dilemmas of Race, Identity, and Success at Capital High. (Chicago: University of Chicago Press, 1996).

[34] Fordham, Signithia and John Ogbu, "Black students' school success: coping with the 'Burden of "Acting White",," The Urban Review, XVIII (1986)

[35] Fryer, Roland, "A Model of Social Interactions and Endogenous Poverty Traps," Rationality and Society, XXX (2007), 335-366.

[36] Fryer, Roland, forthcoming, "Racial Inequality in the 21st Century: The Declining Significance of Discrimination," In Orley Ashenfelter and David Card, eds., Handbook of Labor Economics, Volume 4.

[37] Fryer, Roland and Paul Torelli, forthcoming, "An Empirical Analysis of 'Acting White'," Journal of Public Economics. 
[38] Fryer, Roland and M.O. Jackson, "A Categorical Model of Cognition and Biased Decision Making," The B.E. Journal of Theoretical Economics (Contributions), VIII (2008), $1-42$.

[39] Fryer, Roland and Steve Levitt, "The Causes and Consequences of Distinctively Black Names," Quarterly Journal of Economics, CXIX (2004), 767-805.

[40] Fryer, Roland and Steven D. Levitt, forthcoming, "Testing for Racial Differences in the Mental Ability of Young Children," American Economic Review.

[41] Guryan, Jonathan, "Desegregation and Black Drop-Out Rates," American Economic Review, XCIV (2004), 919-944.

[42] Hoover, Edgar M., "Interstate Redistribution of Population, 1850-1940," Journal of Economic History, I (1941), 199-205.

[43] Jahn, Julius A., Calvin F. Schmid, and Clarence Schrag, "The Measurement of Ecological Segregation," American Sociological Review, CIII (1947), 293-303.

[44] Jencks, Christopher, Inequality: A Reassessment of the Effect of Family and Schooling in America. (New York: Basic Books, 1972).

[45] Jencks, Christopher and Meredith Phillips, eds., The Black-White Test Score Gap. (Washington, DC: The Brookings Institution Press, 1998).

[46] Kain, John, "Housing Segregation, Negro Employment, and Metropolitan Decentralization," Quarterly Journal of Economics, LXXXII (1968), 175-197.

[47] Lindbeck, Assar, Sten Nyberg, and Jorgen Weibull, "Social Norms and Economic Incentives in the Welfare State," Quarterly Journal of Economics, CXIV (1999), 1-35.

[48] Lundberg, Shelly J. and Richard Startz, "Private Discrimination and Social Intervention in Competitive Labor Markets," American Economic Review, LXXIII (1983), 340-347.

[49] Massey, Douglas and Nancy Denton, "The Dimensions of Residential Segregation," Social Forces, LXVII (1988), 281-315.

[50] Massey, Douglas and Nancy Denton, American Apartheid: Segregation and the Making of the Underclass. (Cambridge, MA: Harvard University Press, 1993).

[51] Mickelson, Roslyn. A., "Subverting Swann: The Effects of First- and Second-Generation Segregation in the Charlotte-Mecklenburg Schools," American Educational Research Journal, XXXVIII (2001), pp. 215-52. 
[52] Milgrom, Paul and Sharon Oster, "Job Discrimination, Market Forces, and the Invisibility Hypothesis," Quarterly Journal of Economics, CII (1987), 453-476.

[53] Neal, Derek, "The Complexity of Job Mobility among Young Men," Journal of Labor Economics, XVII (1999), 237-261.

[54] Neal, Derek, "Why Has Black-White Skill Convergence Stopped?" In Eric Hanushek and Finis Welch, eds., Handbook of Economics of Education. (Amsterdam: Elsiver, 2006).

[55] Neal, Derek A. and William R. Johnson, "The Role of Premarket Factors in Black-White Wage Differences," Journal of Political Economy, CIV (1996), 869-895.

[56] Ogbu, John and Astrid Davis, Black American Students in an Affluent Suburb: A Study of Academic Disengagement. (Mahwah, NJ: Lawrence Erlbaum Associates, Inc., 2003).

[57] St. John, Nancy H., School Desegregation Outcomes for Children. (New York: John Wiley and Sons, 1975).

[58] Suskind, Ronald, A Hope in the Unseen: An American Odyssey From the Inner City to the Ivy League. (New York: Broadway, 1998).

[59] Taeuber, Karl and Alma Taeuber, Negroes in Cities: Residential Segregation and Neighborhood Change. (Chicago: Chicago Aldine Publishing Co., 1965)

[60] Thernstrom, Abigail, "The Drive for Racially Inclusive Schools," Annals of the American Academy of Political and Social Science, DXXIII (1992), 131-143. 